\title{
The Influence of Covid-19 on the Development of Financial Industry Based on Statistic Analysis
}

\author{
Hengyuan Zhang ${ }^{1 *}$
}

\author{
${ }^{1}$ Form5, The King's Hospital, Dublin, Ireland \\ *Corresponding author: hengyuan.zhang@thekingshospital.ie
}

\begin{abstract}
This paper investigated the impact of the COVID-19 on the Chinese financial industry, which has not been thoroughly researched. This paper analyzed data from three main specific departments in the financial industry, including banking, insurance, and securities. At the same time, some comparisons between the situations before and after the outbreak of the pandemic are shown to give a general understanding of what exactly happened as evidence to support this study. However, after studying these data, although it was found that the situation in China and the world is basically the same, the difference still exists in some internal forms, just like for the banking industry, the general situation of the whole industry keeps in a good trend. Still, now consumers commonly decide to use online banks due to the pandemic. It is predicted that the most situations which are happening now will be kept for many years by changing people's opinions. In application, this is a study focused on the impact on our daily lives, and it is a reference to those investors and researchers on financial analysis.
\end{abstract}

Keywords: Covid-19, Development of Financial Industry.

\section{INTRODUCTION}

\subsection{Research Background and Motivation}

The outbreak of COVID-19 may be one of the biggest Black Swan incidents of the 21st century. From December of 2019, although the Chinese government was trying to prevent its spread, it still became a global disaster. Every country suffered a lot because of it, especially in the aspect of the economy. Based on the data online, the majority of main economic entities have a minus growth rate during the past year, except China and Turkey. However, it does not mean these two countries' industries are fully intact. If we go deeper, we can find that those industries are all received different costs, but after, they are kept in a quite stable "house" built by policies that government introduced. And in this essay, we are focused on the Chinese financial industry.

Among those factors, the financial industry is an important component of China's economy (about 7.7\% of the total GDP). Finance is a very broad concept, and it includes several different parts, such as insurance, stock market, securities, and commodities. Before COVID-19, the Chinese stock market fluctuates around a balance point. Still, during the pandemic, it has experienced a period of decrease, the SSEC (Shanghai securities composite index) dropped from about 3127 to about 2646. However, after few months, under the newly introduced policies and quite good response, the index increased again and went to about 3731 points on another March, that means after one year, the pandemic in China had been curbed. People start to hold a positive thought through the post-pandemic era. Meanwhile, the financial industry, one of the most daily life-related industries, is starting to re-increase and act much more frequently.

\subsection{Literature Review}

Some scholars have already studied some topics about the influence of coronavirus around the global scale. Darius and Stefanos discovered that in worldwide, it is in trend to sell the risky assets for cash and fewer purchases of risky assets to make sure they do not suffer much cost from the crisis [1]. This is a very common behaviour for most people when envisaging those crises, and also for the stock market, Rakesh and Prabheesh pointed out that the pandemic has a negative impact on the stock market, and expressed by the uncertainty and reduction of the stock 
return in worldwide[2]. And in the aspect of the exchange rate, they think during the period, most economies have experienced exchange rate volatility and depreciation due to the cash out flow and the market reaction [3]. This is not exactly accurate because some countries may have more cash in flow than before, especially those "safe havens" for example, gold and swiss franc. And back to the stock market, there are also some special examples during this period, like in Japan, the depreciation of its currency to the US dollar will cause an increase in the stock return, few months after the breakout of the pandemic, the rate kept around $0.588 \%$ decrease to the US dollar. It improved the return about $71 \%$ of average [4]. And one of the most important parts of the financial industry is insurance. It is the most related sector of our daily life, as COVID-19 caused a high unemployment rate, which means more people lose their health coverage paid by firms. Garrett and Gangopadhyaya estimated that there would be at $20 \%$ unemployment and about 25 million people will lose ESI (Employer-sponsored health insurance) and approximately 7 million people will become uninsured. Other people will choose to get other types of insurance [5]. As for the Chinese insurance industry, all the commercial insurance premium income, density of insurance, and depth of insurance, have all increased due to the COVID-19 [6]. So we can see, the global insurance industry is facing the same big problem as the whole industry does. Finally, all the money will be put in or withdrawn from the banks. Still, because of the strong policies towards the banks in order to keep the daily run of a country's economy, so it did not really suffer a lot during this period, just like Aldasoro, Fender, Hardy and Tarashev wrote in their essay, they claim that those strong policies introduced since March have favored banks with higher profitability and healthier balance sheets[7]. And also, this pandemic incited people to put their money into the bank. Neef and Schandlbaue think that due to the accumulation of deposits, banks have more money to increase their loan supply, and they decrease the committee needed to pay and start to issue some new term loans [8]. Generally, for those investors, including countries, individuals, funds, and institutions, the pandemic created an unprecedented level of risk, making them receive a great cost during a short period [9]. While looking for those sources, it is found that there are not a lot of essays focused on this topic. Based on this, this paper decided to investigate this topic - the influence of COVID-19 on the financial industry during the postpandemic era, and it is very significant. And it is aimed to help people understand more about the pandemic and know how it will influence our life-related industry.

\subsection{Research Contents}

In this research, those aspects below have been analyzed. The first is the financial industry's current situation and it is compared with the situation before the outbreak of COVID-19 to show the difference between them. Second, this paper started from different perspectives of different apartments in this industry and had a deeper research on those significant changes during this period, and this paper also compared it with some foreign countries' financial industry to show the difference or the common characteristics of the changes among different financial situations. Third one is the research on how it changed. Then the essential reason that caused this change have been investigated and some advice have been given on keeping sustainable development for the financial industry in the postpandemic era.

The structure of this essay is shown below. The first part is an introduction, mainly introducing the research background and the significance, and this paper listed some literature concerning research of the financial industry during COVID-19. The second part is the source of data and the analysis. This paper discussed the changes of those specific apartments in the financial industry before and after the pandemic outbreak. The third part is the result and discussion. And the last part is the conclusion of the research.

\section{METHODOLOGY}

\subsection{Data Sources}

This paper used different charts from different sources below, for the analysis of the global financial situation, all the figures are from Investing.com. Figure 5 is from CEIC. Figure 6 is from CFCA, and figure 7, 10, and 11 are from iimedia research. Figure 7 and figure 8 are from STCN. Figure 12 is from qianzhan industry research institute, and 13 is from jingribao.163.com. Figure 14 is from http://finance.sina.cn and figure 15 is from www.nffund.com. As for 16 and 17, they are both from Financial Times, and the 18 is from http://cishan.chinapo.gov.cn. Table 1 and Table 2 are from eastmoney.com and the People's Bank of China, respectively.

\subsection{Data Analysis}

\subsubsection{Current situation of International Finance}

The impact of COVID-19 on the financial industry worldwide is a very extensive topic. Based on this, this paper started from the stock market, which is the epitome of the whole industry and checked some 
changes of important indexes in the EU, the USA,

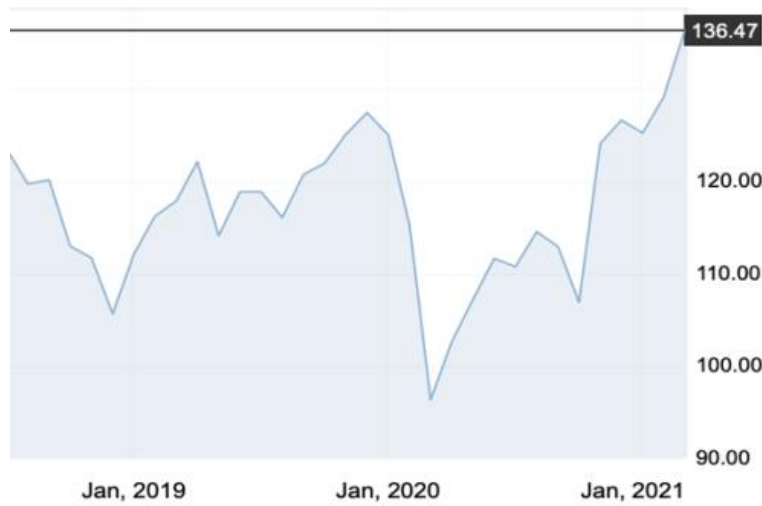

Fig.1. MSCI EU Overview - 5-year range

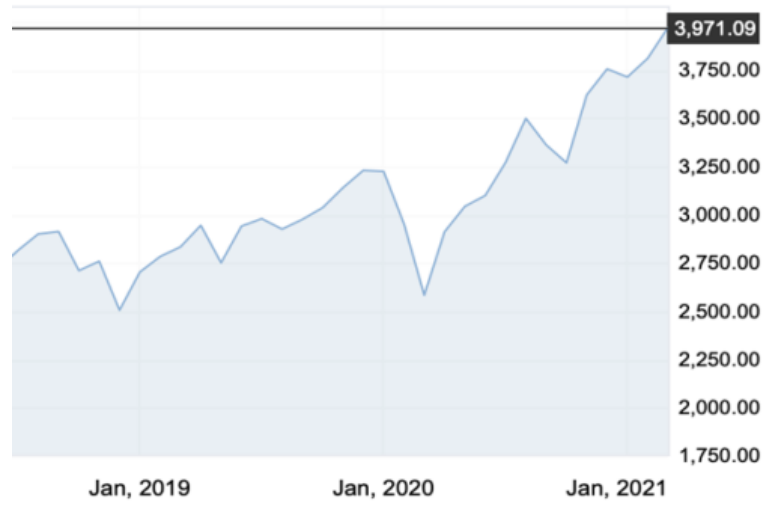

Fig.2. S\&P 500 - 5-year range of American

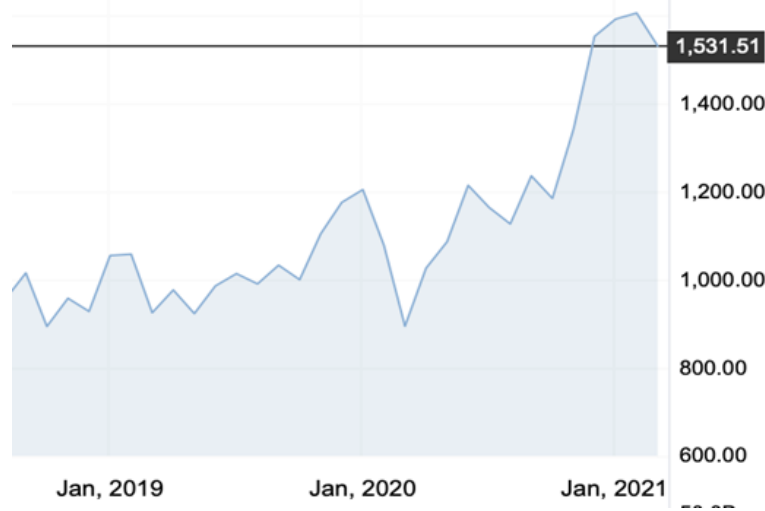

Fig.3. BIST Istanbul - 5-year range of Turkey

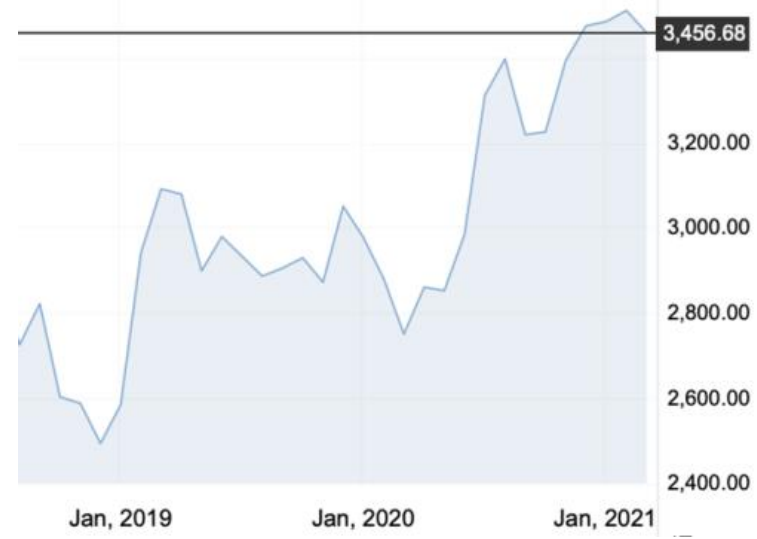

Fig.4. Shanghai Composite overview- 5-year range
Turkey, and China.

From figure 1, we can easily see that during the December of 2019, there was a big decrease in the MSCI, and it dropped to under 100 points. Then it climbed back a little bit later, but on the 1st of October, there was the second decrease, that shows the situation at that time was turned to bad again. From figure 2, as the reference of the American stock market, we can see it also fell back in December 2019, it also experienced the second fall in October in 2020. Turkey is shown in figure 3, the same as in the American. And as for China, where the virus had been discovered first, its situation is also keeping in a reasonable range as the world. Based on those figures shown, this paper has a preliminary result that the financial industry had a big reaction towards the crisis beginning around December 2019 and had another one around October 2019, when exactly the virus had been discovered and got worse.

\subsubsection{Industry analysis}

As for this part, this paper analyzed those particular departments in the financial industry respectively with some assistance of charts and comparisons to elaborate the similarity or difference of impact of COVID-19 on those parts.

\section{(1) Banking and relevant industry}

The bank is very important to the current financial environment, and it helps to give loans, issue bonds, and print money, etc. It is also very related to our daily life, like we can put our money there. Similarly, if any crisis happened, the bank would be the first object that would be influenced.

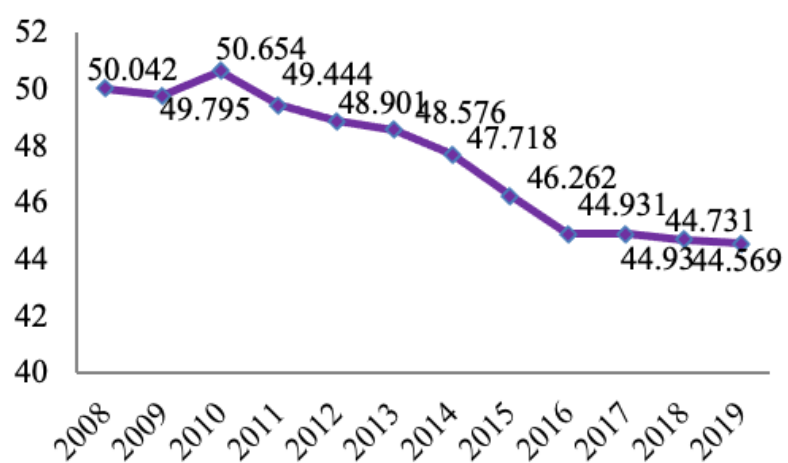

Fig.5. Gross Domestic Saving Rate: Annual: China

We can see from figure 5 above that there is a big drop in the saving rate from 2010, and it had been lasted for 6 years till 2016 and kept at a flat rate of around $44 \%$. This is because some Chinese financial companies launched few new online investing applications so that most people started to have financial awareness and tried to invest instead of just put in the banks. We will also talk about this part later. In addition, we can find that at the end of 2019, the rate is still keeping at $44.569 \%$ and just a little bit less than last year, but for 2020, it 
jumped to $33.9 \%$ based on the research of Goldman Sachs and expected to reach $34 \%$ by the end of 2021 . That means more and more people in China are starting to withdraw their money from the banks during 2020 , which is also the climactic period of the pandemic. And also, more money is flowing to the stock market and other financial media.

Table 1. Data of stock market account(2019.12 to 2020.11)

\begin{tabular}{|c|c|c|c|c|c|}
\hline Date & $\begin{array}{c}\text { Increased } \\
\text { accounts }\end{array}$ & $\begin{array}{l}\text { Ratio to last } \\
\text { month }\end{array}$ & $\begin{array}{c}\text { Number of } \\
\text { accounts }\end{array}$ & Market value(total) & $\begin{array}{l}\text { Change in } \\
\text { SSEC }\end{array}$ \\
\hline 2020.11 & 152.7 & $36.34 \%$ & 17615.31 & 76.95 & 5.19 \\
\hline 2020.10 & 112 & $-27.33 \%$ & 17462.6 & 73.58 & 0.2 \\
\hline 2020.9 & 154.1 & $-14.14 \%$ & 17350.59 & 72.17 & -5.23 \\
\hline 2020.8 & 179.5 & $-26.01 \%$ & 17196.46 & 75.95 & 2.59 \\
\hline 2020.7 & 242.6 & $56.64 \%$ & 17016.95 & 73.82 & 10.9 \\
\hline 2020.6 & 154.9 & $27.58 \%$ & 16774.32 & 64.88 & 4.64 \\
\hline 2020.5 & 121.4 & $-25.99 \%$ & 16619.42 & 60.01 & -0.27 \\
\hline 2020.4 & 164 & $-13.26 \%$ & 16498 & 59.4 & 3.99 \\
\hline 2020.3 & 189.1 & $111.2 \%$ & 16333.96 & 56.29 & -4.51 \\
\hline 2020.2 & 89.54 & $-11.83 \%$ & 16144.84 & 59.66 & -3.23 \\
\hline 2020.1 & 80.07 & $-1.06 \%$ & 16055.30 & 59.72 & -2.41 \\
\hline 2019.12 & 80.93 & $-2.08 \%$ & 15975.24 & 59.29 & 6.20 \\
\hline
\end{tabular}

Source: eastmoney.com

The unit of Increased account and number of accounts is ten thousand, the unit of value is one trillion yuan.

As Table 1 shown, we can find that started from March of 2020, when the pandemic began to become serious, more people chose to put their money into the stock market, and the highest reached about $111.2 \%$ times last month in March but compared to the global index trend which started to fall from December in 2019, those individuals still do not have enough information or some of them are afraid to take the risk. Generally, after about one year, the total amount of individual investors in the Chinese stock market had increased by about 1700 thousand, and the total value had increased by about 17 trillion yuan, which is a significant number. This is another proof of the decreased savings of households as they invest more, save less. And also, another thing which is stealing "food" from virtual banks are online banks, distinguished from the conventional banks, they are more convenient, and without those multifarious procedures, these characteristics make it become popular among those young people and some elders, and the mobile bank is the biggest component, as a report shows that in 2020, there are about $71 \%$ people in China use the online 
mobile banks and had increased by $12 \%$ than last year, this is also because of the pandemic, people can not even go outside, let alone go to the virtual banks for checking deposit or get money from there [10]. Therefore online banks are very easy to become substitutes

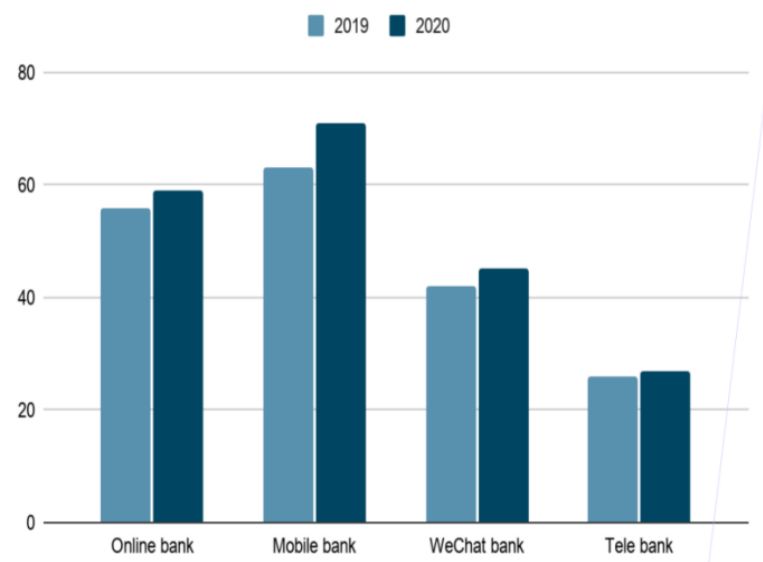

Fig.6. Percentage of users of online banks ) unit: \% (

From Figure 6, we can clearly see that more users are starting to use online banks during 2020, which corroborated the statement this paper made above. Concerning another aspect, if the online banks are used much more often, those users will also use some of the investment functions that come with mobile banking. For example, you can invest in financial management like the stock market or put your money into funds. Compared to traditional financial management, online finance has the same advantages as an online bank. It can make it easier to put in or withdraw money, especially during the pandemic.

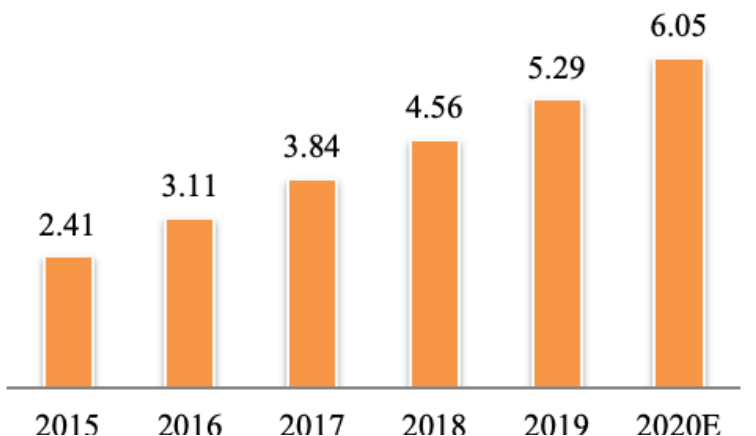

Fig.7. Scale and Forecast of China's Internet Financial Management Users 2015-2020

Apart from this, it also forecasts that until 2020, China's internet financial management will reach about 15.5 thousand billion yuan, which also means the great number of money will not flow into the market via conventional banks, which is a big challenge for those virtual banks. Let us back to conventional banks. If you check the assets and liabilities of the banking industry, you will find there are very few influences towards it. (see as below).

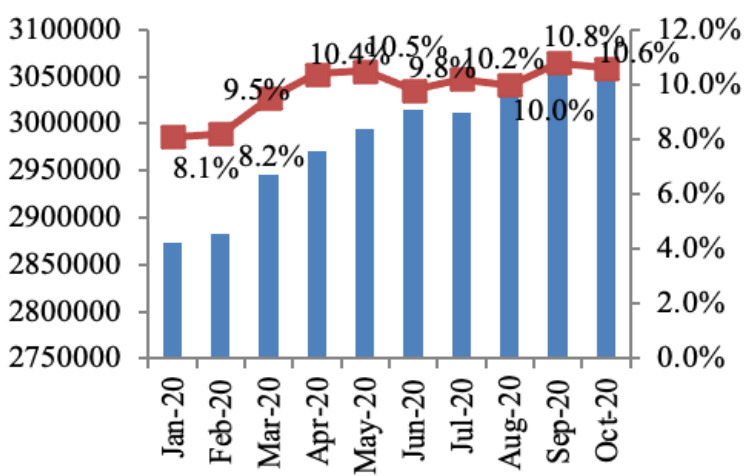

Fig.8. Total assets of financial institutions

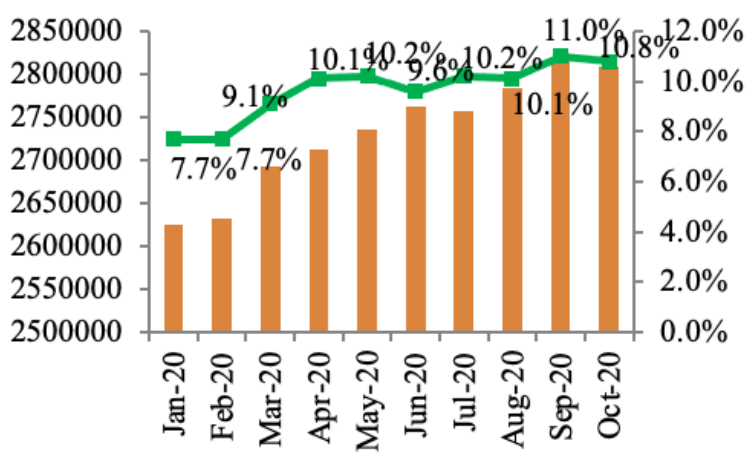

Fig.9. Total liabilities of financial institutions

Based on figures 8 and 9, we can find there is not a very big difference between the general amount of assets and liabilities of the banking industry before or after the outbreak of COVID-19. All the indexes are fluctuating around a normal rate. Therefore that means when the pandemic happened, most people would still trust the bank system and keep money inside. Even if some people withdraw their money from banks, they still have enough assets to deal with it. Generally, banks will not suffer much due to the pandemic. Still, the thing that would make banks receive a higher cost is choosing another convenient way to check or deal with our money. Such as the mobile banks, especially the new internet companies with their updated products, like Alipay and WeChat bank, they are challenging those conventional banks' position by attracting more deposit. Especially after the global pandemic, those restrictions make consumers hard to get to those banks physically, so put money online became an excellent idea for them. The investment also got some of those deposits from banks, and some people may not trust the bank during big crises, so after the outbreak of COVID19 , they just withdrew their money from the bank and put them at home invested them in finance. Here, the financial function with an online bank also helps them make choices because it is easy to do or get money back, making people choose to invest more.

Conversely, more people put their money into an investment, more profit they can make, and could cause a bull market. After the pandemic, the saving rate might 
go back to the normal level as before, more money will be put back into banks, and banks could get more interest too, it is a virtuous circle, therefore it may not be a bad thing for the banking industry.

\section{(2) Insurance}

As another big component of the financial industry, and it is also very important to our daily life, the insurance industry kept having a greatly increased amount during the past few years. And also, due to the increase in China's household disposable income, this sharply increasing process is guaranteed by stable cash flow.

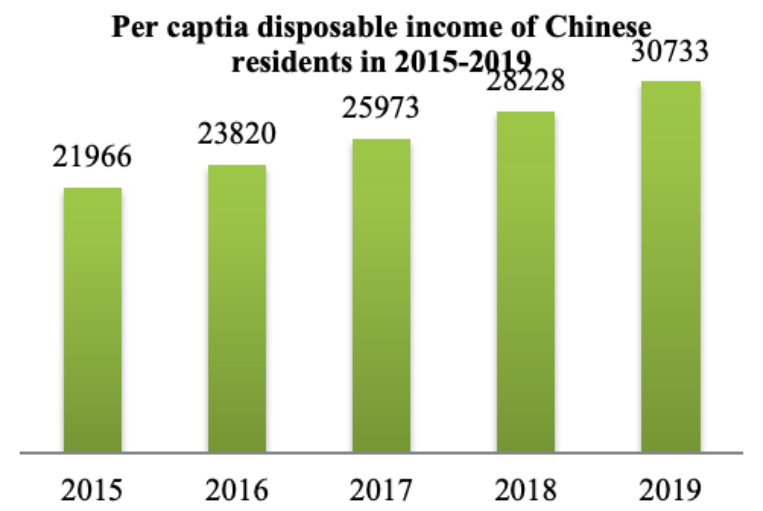

Fig.10. Per capita disposable income of Chinese residents in 2015-2019

However, due to the outbreak of COVID-19, the insurance industry received a great reduction in their performance, Haegeli predicted that the economy is expected to shrink by about $4 \%$ this year, which is more severe than the recession during the global financial crisis of 2008-2009, but the scale of the shrinkage in premiums is similar [11]. That means the insurance industry is still flexible and strong enough to deal with the current crisis worldwide. Let us look back at China's situation. We will find there was still a decrease around February and March due to the severe situation at that time, and there was a about $14.4 \%$ decrease in the total income of insurance at the end of February.

\section{Comparison of monthly premium income of China's insurance industry from January to August 2020}

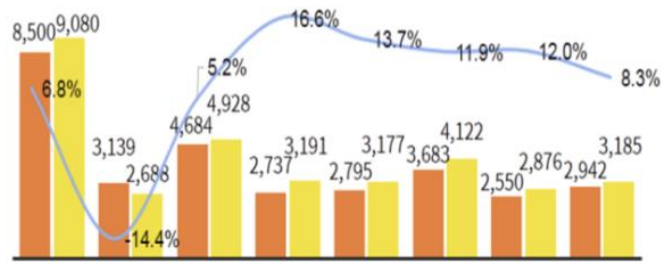

Fig.11. Comparison of monthly premium income of China's insurance industry from January to August 2020

From figure 11, we can also find that apart from February, the sum of income of the insurance industry compared to other months still had a good increase.
What is the reason? One research shows that saving products will be hardest hit in life, and in non-life, travel, and trade-related lines will suffer most. Rate hardening in commercial lines will support profitability in non-life; rising risk awareness due to COVID-19 will support premium growth across many lines of business over the longer term [12]. That means although people stop putting their money into saving insurance, still, because of the global pandemic, health became one of the most focused topics, therefore people would choose to transfer their money from saving to health insurance more. According to data from the China Banking and Insurance Regulatory Commission, from January to May, health insurance premium income was 392.7 billion yuan, a year-on-year increase of $20.3 \%$, the highest growth rate among all insurance types.

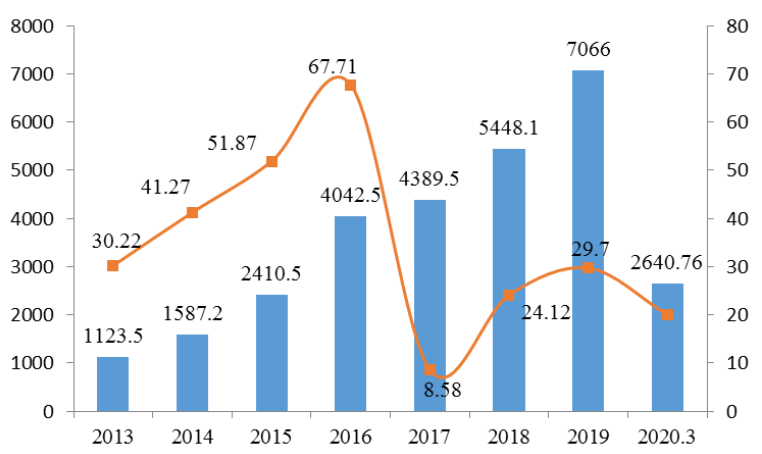

Fig.12. Statistics and Growth of China's Health Insurance Premium Income, 2013- First Three Months of 2020

Therefore, the reaction of the insurance market towards the pandemic is not very strong, and it more prefers to perform by transference of money from one risky part, for example, the saving insurance, to a safe part of a beneficial part, for example, health insurance during a pandemic. In general, the insurance industry's total value will not have many changes, all the changes are internal under the big frame, or even their fear of being sick may stimulate the consumption of health insurance as above. After the pandemic, although everything will go back to normal, the awareness of life safe will become more important to everyone. We can compare it with SARS (2002-2003).

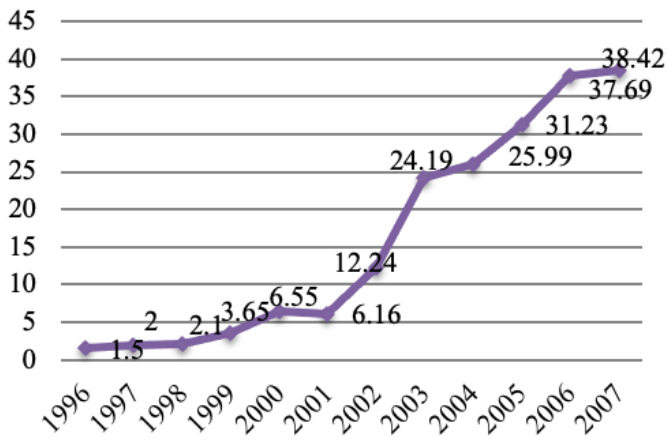

Fig.13. The proportion of commercial health insurance in total health expenditure from 1996 to 2007 
From figure 13, we can see that started from 2002, there is a trend to have a big increase in the proportion of health insurance, and that was exactly when the SARS happened, and after 2003, when the pandemic finished, the trend of the line still kept in a high rate and fluctuated around it. That verified my statement above, as well as today's situation. After COVID-19, people will put more money into health insurance, and it will get to a higher stage than before.

\section{(3) Securities industry}

Though the securities industry is not as big as banking or insurance, it is still very important and grows at a fast rate.

Table 2. Total assets of the security industry

\begin{tabular}{ccc}
\hline & Outstanding & $\begin{array}{c}\text { YoY Growth } \\
\text { rate }\end{array}$ \\
\hline 2019Q1 & 7.78trillion & $9.6 \%$ \\
2019Q2 & 7.88 trillion & $11.2 \%$ \\
2019Q3 & 7.83 trillion & $13.6 \%$ \\
2019Q4 & 8.12 trillion & $16.6 \%$ \\
2020Q1 & 8.83 trillion & $13.5 \%$ \\
2020Q2 & 9.04 trillion & $14.8 \%$ \\
2020Q3 & 9.7 trillion & $23.9 \%$ \\
\hline
\end{tabular}

Source: Statistics and analysis department, The People's Bank of China

We can see from Table 2, from the Q3 of 2019 to the Q3 of 2020, the growth rate had been increased by about $10 \%$, and its total value had been increased by about 10 trillion yuan. This paper has already analyzed a little of it in the banking part by giving the data showing the increased number of market accounts to discuss the impact of the pandemic on the banking industry. But there is not only the stock market in the range of securities but also bonds and funds and other types of financial derivatives.

As Gubareva(2020) says in his research, the $\mathrm{EM}$ (emerging market) countries and economy are more resilient to liquidity shocks than the non-EM corporate and sovereigns[13]. We can see that as one of those emerging markets, China's securities market achieved significant progress during the pandemic.

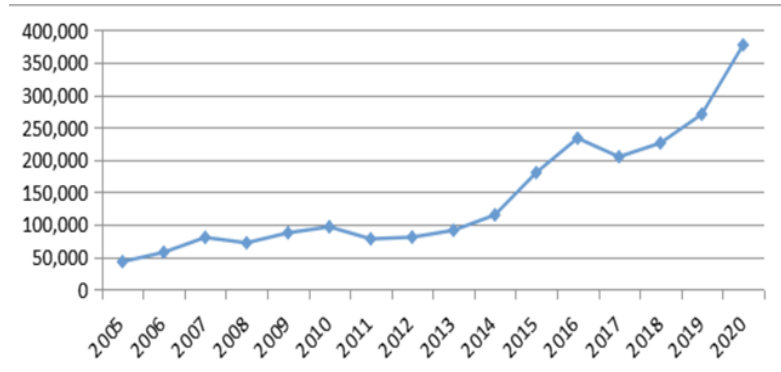

Fig.14. 2005-2020 Bond Market Issuance Volume
Especially during 2019-2020, there was an another big increase in bond issuance, most proofs show that China has a very stable market quotation, and it is keeping this trend for few years, and I am sure, after the pandemic, it still gonna keep at that rate for many years. As for the part of funds, we can get into the topic by the newly launched funds.

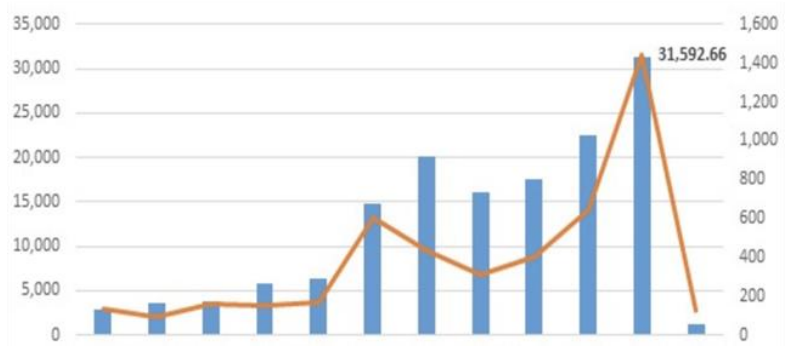

Fig.15. 2010-2021 number and scale of new funds

From figure 15, we can see that during 2019-2020, there was a big step of increase in the newly launched funds, compared to before, the performance of the funds' situations during the pandemic is better than usual, it also verified what did Gubareva state above. Therefore for China, there is always a situation for securities during big crises. Though this paper only used a short paragraph to analyze the security part (including few parts in the banking section), it still shows a very positive trend under the pressure of the pandemic. At the climax of the pandemic, it showed an opposite situation from the other industries. Although the pandemic caused some fluctuations on the whole securities industry first, because of the good organization, the market started to rebound again and became one of the leading powers of the economy's growth.

\section{(4) Others}

There are also some other parts of the financial industry that this paper has not discussed yet, for example, the leasing industry. For this part, most of those companies suffered a lot during the pandemic. Still, among those, the Aviation leasing industry had the worst performance during the pandemic due to the impact of COVID-19 on international traveling and those restrictions introduced by countries, the demand of traveling by aircraft had been reduced a lot, we can also see that from the stock price of aviation companies:

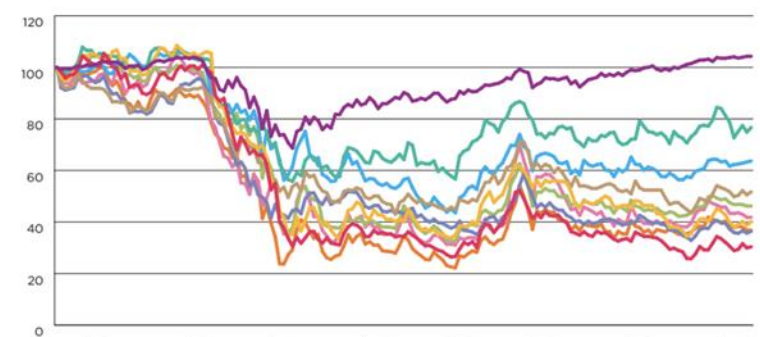

Fig.16. Airline stock performance so far in 2020 
Now, let us have a look at the price of the aviation leasing companies:

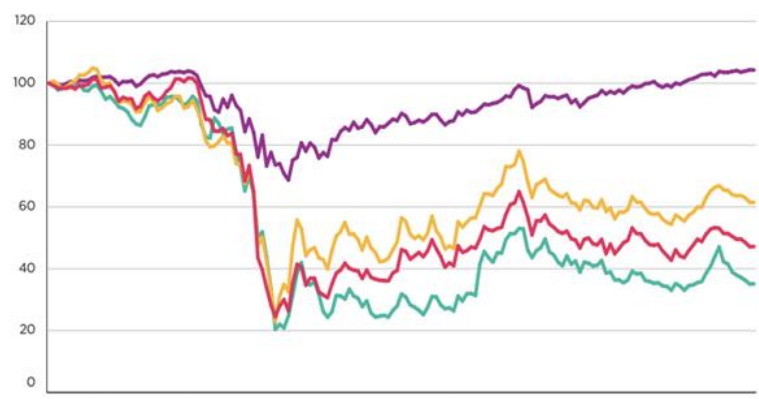

Fig.17. The share price performance of major leasing companies listed in the U.S. so far in 2020

We can easily see that these two stock prices have a very strong connection. From March of 2020, the prices just started to fall due to the pandemic situation also started to get severe, and till now, it is still hovering around the lowest point. This paper predicts this situation will still exist until the end of the pandemic. As for the trust industry, there are both advantages and disadvantages. After the pandemic, the government must plan to put more money into the basic infrastructures to hedge the risk brought by the pandemic, and those trust companies will have more opportunities. The health and medicine industry will also attract more focus of government and more finance from investors. Moreover, charitable trusts will have more support from the government as a big part of finance for fighting against the pandemic.

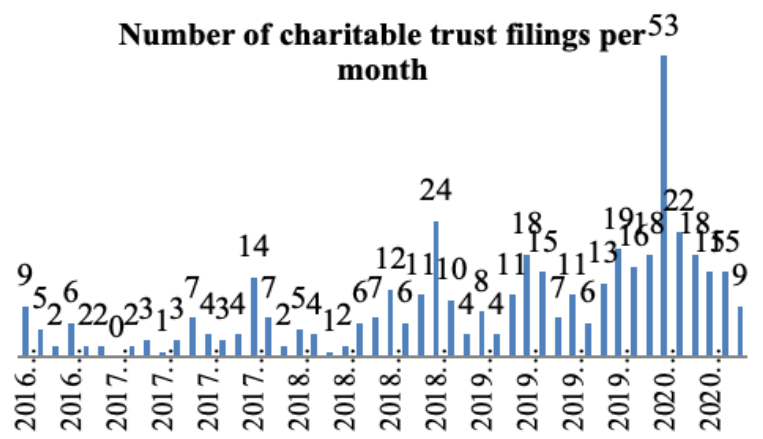

Fig.18. Number of charitable trust filings per month

Figure 18 shows that in March of 2020, there was a very significant number of filed trusts, and that is also the month in which the government or the people need the most help, so obviously, it verified my point above. And although the number is dropping, it will still last for a period of time as the leasing industry does.

\section{RESULTS AND DISCUSSION}

This paper analyzed the financial and industrial development situations in different departments before and after the pandemic by collecting the data. For the first, it described the characteristics of those changes in the global financial environment by listing the trend of the stock markets from the US, the EU, Turkey, and China, respectively, and especially focused on the changes before and after the pandemic. Meanwhile, the banking industry, insurance industry, and the securities industry are analyzed horizontally and vertically to get the comparisons of results. At last, there was a general analysis for the other parts, which are not as important as those three. The results are shown below.

\subsection{Banking Industry}

For this part, this paper chose some figures from the aspects of the saving rates, increased stock market accounts, and some parts related to the online banks. The results show that there is a decreasing trend in the saving rate of Chinese citizens. From the second figure here, it is easy to see that more investors are joining the stock market these years. Especially after the outbreak of COVID-19, same as Table 1, it verified the statement above as the new trend of the methods for Chinese to deal with money they earn is to put it into the stock market rather than put into banks more. Under the pandemic pressure, it is a wiser way to invest money than putting in the bank to hedge the risk. That means combining these two needs is taking China's banking industry and the whole financial industry into a new situation, and this paper predicted that this situation would last for a long time after the pandemic. As for another significant part, this paper analyzed the online banking sector too. As the launches of the new online banking applications, more and more people start to find the advantages of online banks. Figure 6 to figure 7, which showed the percentages of online bank and online financial management products, clearly shows that there is a rising trend during the last few years. Between 2019 and 2020, it archived another big step of numbers of users.

Generally, as this paper analyzed, there are not lots of changes in the banking industry. The majority of those changes are internal, as money goes from the banking to the investment such as stock market, and more people start to choose the online services, it much more prefers to show as the change of the methods and thoughts. These changes are going to last for many years.

\subsection{Insurance Industry}

This part, the paper started from the data of the disposable income of Chinese residents(shown as figure 10), it shows a rising trend, then as figure 11 to 12 shown, the income of the Chinese insurance industry and specifically the health insurance has a sharp growth during the pandemic, it is very understandable, because of the COVID-19, a type of virus, which is able to make people die, so they started to care about their health 
more, and they are going to pay more on it. As the same to Figure 13, the proportion of citizens' income to the total expenditure is taking a more important place in real life with growing attention on this aspect. The increases in the products of health and the death of the pandemic attracted more money to the charities, especially the charity for those who have gotten the illness, it is known as the health charity. This paper also compared the current situation with a former disaster called SARS, which happened in 2002-2003. And the result shows a similar situation with COVID-19, as there are both big investments in the health industry.

All in all, the pandemic would make it receive some kind of costs at the beginning as the same to the banking industry. Still, after a part of the time, the money will come back to the market or industry, and it is another transfer of money under the whole industry as they withdraw money from the saving parts to the healthy parts. And as this paper predicted, this situation is still going to last for many years because of the rise of people's health sense.

\subsection{Securities industry}

China's securities industry is always keeping at a high growth rate. As an emerging market, China's market shows a very stable situation. Even during the pandemic, it still keeps its speed. Moreover, the rate is still rising. It also verified the statement which did this paper make above - those saved money from banks are putting into the investment. If contrasting Table 1 with figure 14 and figure 15 , it is also very clear that there is some connection between them. About bonds, this part is experiencing the same situation as most parts of the industry do. It is also a beneficiary under this big trend. There is not much change here due to the special market situation, but the only thing that this paper could say is that it will keep this trend for a long time.

\subsection{Others}

The trend of the general financial industry in China had a very normal increasing or decreasing process. Suppose we check the stock price or index of most financial companies or derivatives. In that case, we can find that most of them had a reduction in December 2019 and had another big one in March 2020, and they just fit the time when the pandemic had been discovered and when it started to get severe. The market is very pure; those investors only react towards the risk of one market, and after the crisis or if the country has done a quite good job, they will come back to the market again. So that is why this paper said the price can always go back to normal after the pandemic.

\section{CONCLUSION}

After the outbreak of the COVID-19, there were lots of articles and papers published researching on the topics such as politics, economics, and health expenditure, but not much in the aspect of finance, so this paper is decided to investigate the impact of the pandemic on the financial industry to fill the vacancy. After researching the different departments of the financial industry, this paper found that there are some very similar situations among those three parts (banking, insurance, and securities) that have been analyzed the most. Some other parts (the others), is that after the pandemic, the general situation will not be changed a lot due to the different government form and market situation, it much more prefers to be shown as a change of the form of services, such as the more frequent use of online banks and the online investment management is a type of changes in the banking industry. And apart from that, everything is still in coordination with the global financial situation, as this paper analyzed at the beginning. And for the future, what the government should do is to try to keep it at a stable rate by making more policies, and generally, it is going in a good trend due to the good and quick organizations, and we should not worry about it too much. And this is also the advice given to those investors and institutes, the situation is going in a very positive direction, and a loss will become a benefit soon.

For this topic, it is very important and significant to investigate, because there were not much papers researching on it. Also, finance is a very important part of the current economy, we can learn a lot from the changes of financial situation and try to avoid those coming dangerous to give the citizens a peaceful life and a better developed environment.

\section{REFERENCES}

[1] Wójcik, D., \& Ioannou, S. (2020). COVID - 19 and Finance: Market Developments So Far and Potential Impacts on the Financial Sector and Centres. Tijdschrift voor economische en sociale geografie, 111(3), 387-400.

[2] Padhan, R., \& Prabheesh, K. P. (2021). The economics of COVID-19 pandemic: A survey. Economic Analysis and Policy.

[3] Padhan, R., \& Prabheesh, K. P. (2021). The economics of COVID-19 pandemic: A survey. Economic Analysis and Policy.

[4] Narayan, P. K., Devpura, N., \& Wang, H. (2020). Japanese currency and stock market-What happened during the COVID-19 pandemic? Economic Analysis and Policy, 68, 191198.Garrett, A. B., \& Gangopadhyaya, A. (2020). 
How the COVID-19 recession could affect health insurance coverage. Available at SSRN 3598558.

[5] Garrett, A. B., \& Gangopadhyaya, A. (2020). How the COVID-19 recession could affect health insurance coverage. Available at SSRN 3598558.

[6] Wang, Y., Zhang, D., Wang, X., \& Fu, Q. (2020). How does COVID-19 affect China's insurance market?. Emerging Markets Finance and Trade, 56(10), 2350-2362.

[7] Aldasoro, I., Fender, I., Hardy, B., \& Tarashev, N. (2020). Effects of Covid-19 on the banking sector: the market's assessment (No. 12). Bank for International Settlements.

[8] Dursun-de Neef, H. Ö., \& Schandlbauer, A. (2020). COVID-19 and Bank Loan Supply. Available at SSRN 3642522.

[9] Zhang, D., Hu, M., \& Ji, Q. (2020). Financial markets under the global pandemic of COVID-19. Finance Research Letters, 36, 101528.

[10]2020 China Electronic Banking Development Report

[11]Doctor Jerome Jean Haegeli, Chief Economist of Swiss Re Group

[12] Global insurance industry to recover strongly from COVID-19 induced pull-back, sigma says, Swiss Re china

[13] Gubareva, M. (2020). The impact of Covid-19 on liquidity of emerging market bonds. Finance Research Letters, 101826. 